\title{
Determinants of gestational night blindness in pregnant women from Rio de Janeiro, Brazil
}

\section{Cláudia Saunders ${ }^{1,2,3, *}$, Maria do Carmo Leal ${ }^{4}$, Paulo Augusto Ribeiro Neves ${ }^{5}$,} Patricia de Carvalho Padilha ${ }^{1}$, Letícia Barbosa Gabriel da Silva ${ }^{6}$ and Arthur Orlando Corrêa Schilithz ${ }^{4}$

'Departamento de Nutrição e Dietètica, Instituto de Nutrição Josuè de Castro, Universidade Federal do Rio de Janeiro (UFR), Avenida Carlos Chagas Filho 373, Bloco J - $2^{\circ}$ andar - sala 26, Cidade Universitária, Rio de Janeiro, RJ, CEP 21941-590, Brasil: ${ }^{2}$ Maternidade Escola, Universidade Federal do Rio de Janeiro (UFRJ), Rio de Janeiro, RJ, Brasil: ${ }^{3}$ Programa de Pós-doutorado em Epidemiologia em Saúde Pública, Escola Nacional de Saúde Pública da Fundação Oswaldo Cruz (ENSP/FIOCRUZ), Rio de Janeiro, RJ, Brasil: ${ }^{4}$ Departamento de Epidemiologia e Métodos Quantitativos em Saúde, Escola Nacional de Saúde Pública da Fundação Oswaldo Cruz (ENSP/FIOCRUZ), Rio de Janeiro, RJ, Brasil: ${ }^{5}$ Programa de Doutorado em Nutrição em Saúde Pública, Faculdade de Saúde Pública, Universidade de São Paulo (USP), São Paulo, SP, Brasil: 'Programa de Pós-graduação em Nutrição, Instituto de Nutrição Josué de Castro, Universidade Federal do Rio de Janeiro (UFRJ), Rio de Janeiro, RJ, Brasil

Submitted 11 November 2014: Final revision received 18 April 2015: Accepted 28 April 2015: First published online 9 June 2015

\begin{abstract}
Objective: To describe the prevalence and determinants of gestational night blindness in pregnant women receiving care in a hospital in Rio de Janeiro, Brazil. Design: Cross-sectional study of pregnant and postpartum women receiving care in a public hospital in Rio de Janeiro from 1999 to 2001 (group I; $n$ 225) or from 2005 to 2008 (group II; $n$ 381). Night blindness was identified through a standardized and validated interview (WHO, 1996). The determinants of gestational night blindness were identified through a hierarchical logistic regression model.

Setting: Public maternity hospital in Rio de Janeiro, RJ, Brazil.

Subjects: Adult pregnant and postpartum women ( $n$ 606), aged $\geq 20$ years.

Results: The prevalence of gestational night blindness was $9 \cdot 9 \%$. The final model revealed that not living in the South Zone of Rio de Janeiro (distal level: adjusted $\mathrm{OR}=1.846 ; 95 \% \mathrm{CI} 1.002,3 \cdot 401$ ), belonging to group I (intermediate level: adjusted $\mathrm{OR}=2 \cdot 183 ; 95 \% \mathrm{CI} 1 \cdot 066,4.471)$ and for the proximal level, having a history of abortion (adjusted $\mathrm{OR}=2 \cdot 840 ; 95 \% \mathrm{CI} 1.134,7 \cdot 115$ ) and having anaemia during the first and second trimesters of pregnancy (adjusted $\mathrm{OR}=3.776$; $95 \%$ CI 1.579 , 9.029) were determinants of gestational night blindness.

Conclusion: Gestational night blindness should be assessed for during the prenatal care of all pregnant women, especially those living in deprived areas of the city and/or who have a history of abortion or anaemia. Nutritional monitoring is recommended during pregnancy to control gestational night blindness.
\end{abstract}

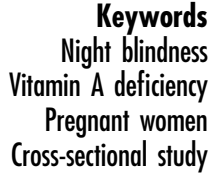

Keywords
Night blindness itamin A deficiency Cross-sectional study
Vitamin A deficiency (VAD) remains an ongoing public health problem in many areas of the world. Children and women of childbearing age are most affected, with an estimated 190 million children of pre-school age and 19 million pregnant women having VAD ${ }^{(1)}$. Based on night blindness (XN; the ocular symptom of VAD) and xerophthalmia (the first stage of ocular manifestations due to VAD), it is estimated that 5.2 million pre-school children and 9.8 million pregnant women are impacted, corresponding to $0.9 \%$ and $7 \cdot 8 \%$ of these populations worldwide $^{(1,2)}$.

A national survey conducted in Brazil examined VAD among children of pre-school age and women of reproductive age ${ }^{(3)}$. Analyses of serum retinol, which is the biochemical indicator of VAD, revealed that women from the Southeast region evinced the highest prevalence of VAD in the country $(14.0 \%)$, surpassing those in the Northeast region $(12 \cdot 1 \%)$, which is considered at higher risk for this 
condition $^{(3)}$. These findings are supported by data from the WHO showing that the prevalence of VAD among pregnant/postpartum women living in Rio de Janeiro, RJ (Southeast region of Brazil) is higher than in those living in the Northeast region, based on gestational $\mathrm{XN}^{(4)}$.

The $\mathrm{WHO}^{(5)}$ considers VAD one of the aggravating factors for maternal mortality because it may be associated with worsening of hypertensive disorders of pregnancy due to the antioxidant role of vitamin $\mathrm{A}$. In addition, VAD contributes to the worsening of puerperal infections because of the effects of vitamin A on the immune system and it is often associated with anaemia in pregnant women $^{(6-11)}$.

Hypertension, haemorrhage and puerperal infection are among the main direct causes of maternal death among Brazilian women ${ }^{(12)}$. The maternal mortality ratio is considered high in Brazil. The Brazilian Ministry of Health estimates sixty-eight maternal deaths per 100000 live births $^{(12)}$.

Thus, the diagnosis of gestational $\mathrm{XN}$ is currently a marker of high-risk pregnancy and may be useful during prenatal care to identify women requiring special attention $^{(13,14)}$. In addition, the prevalence of XN can also indicate nutritional deficiency due to, for example, acute changes in living conditions, economic crises or reduction in employment rates, which affect the prevalence of $\mathrm{XN}$ in pregnant women and pre-school children ${ }^{(15)}$.

Inadequate dietary intake of vitamin $\mathrm{A}$ is the most recognized risk factor for $\mathrm{VAD}^{(2,8,16-18)}$. However, other factors need to be further studied, such as lack of education, poor sanitation, food insecurity, low maternal socioeconomic status, poorly diversified and plant-based diets and low consumption of vitamin A-rich foods, whose association with VAD has been well described in studies conducted in Asia and Africa ${ }^{(16,19,20)}$. In Brazil, such studies remain inconclusive. The majority of the available studies were conducted in the Northeast region, a region classically recognized as having a higher prevalence of VAD among children ${ }^{(4)}$. The determinants of gestational $\mathrm{XN}$ in the country are still not clear, stalling the adoption of effective measures to prevent and control this condition.

The present study aimed to describe the prevalence of gestational $\mathrm{XN}$, and identify the factors that determine this ocular symptom, using a hierarchical analysis in adult pregnant women who received care in a hospital in Rio de Janeiro, Brazil.

\section{Methods}

\section{Study population and inclusion criteria}

The present cross-sectional study is part of the project entitled 'Health and Nutrition Profile of Postpartum Women and Newborn Infants in the Maternity Hospital of the Federal University of Rio de Janeiro during 1999-2008' (Perfil de Saúde e Nutrição de Puérperas e Recém- nascidos da Maternidade Escola da UFRJ no período de 1999-2008; Principal Investigator C Saunders; Sigma/ Universidade Federal do Rio de Janeiro (UFRJ) registration number 19022, March 2010) and was conducted with a representative sample of pregnant/postpartum women receiving care in this hospital from 1999-2001 ( $n$ 225) and 2005-2008 ( $n$ 602), totalling 827 women.

The maternity hospital studied is associated with the Brazilian Public Healthcare System and has prenatal clinics for both low-risk and high-risk pregnancies. A multidisciplinary team provides care to pregnant/postpartum women and newborns. On average, approximately 2100 births are performed annually. Patients receiving care in this hospital are similar to patients (pregnant/postpartum women) receiving care in other health-care units of the city $^{(21)}$. They are similar to Brazilian women of reproductive age evaluated in a national survey ${ }^{(3)}$, based on marital status, skin colour and the prevalence of both elevated BMI and obesity. In addition, postpartum women evaluated in a national hospital-based study, 2011-2012 $2^{(22)}$, were similar to the present sample based on marital status and skin colour.

\section{Study groups}

Taking into consideration the original study, we selected 606 women who met the inclusion criteria: adult (aged $\geq 20$ years) with a singleton pregnancy, without chronic diseases, attending prenatal care and who delivered in a public maternity hospital in Rio de Janeiro. Of the total ( $n$ 606), 225 (37.1\%) women were followed in prenatal care and had their births in the period 1999-2001 (group I; GI) and $381(62.9 \%)$ were followed in prenatal care and had their births in the period 2005-2008 (group II; GII).

Selection of GI occurred at the time of admission to the maternity ward for delivery and/or immediately postpartum (up to $6 \mathrm{~h}$ after birth). Women who met the inclusion criteria and agreed to participate in the study were interviewed. In addition, the medical records of the pregnant woman and her child were reviewed. Selection of GII was done via the original study, in which women were enrolled in the waiting room for prenatal consultations in the studied maternity ward. The same data collection techniques were used for GII as for GI. Data were collected by a team of investigators with expertise in pregnancy and postpartum care, and who were properly trained and supervised.

\section{Nutrition assistance during prenatal care}

During the years 1999-2001, prenatal nutritional assistance offered in the hospital was limited, individualized care with a nutritionist during prenatal care was rare, and any assistance was often initiated late in pregnancy for pregnant women exhibiting weight deviations or pregnancy complications $^{(23,24)}$. There was no minimum number of appointments 
throughout the pregnancy and no definition of the ideal gestational age for referral to the nutritionist ${ }^{(23,24)}$.

Studies conducted in this hospital led to changes in the prenatal routine beginning in 2005. It was found that at least four visits with a nutritionist during pregnancy, starting concomitantly with prenatal care, improved perinatal outcomes. Prenatal care was restructured with the expansion of nutritionist coverage to all pregnant women. Low-risk pregnant women attend at least one group visit with the nutritionist during pregnancy. Risk is monitored throughout pregnancy based on BMI and pregnancy complications (e.g. anaemia, gestational diabetes, hypertension, digestive symptoms), with a minimum of four individual consultations and a maximum interval of $30 \mathrm{~d}$ between them ${ }^{(23,24)}$.

During the consultations, a nutritionist provides teaching and encouragement to consume vitamin A from natural sources and vitamin A-fortified foods. Multivitamin supplementation containing vitamin $\mathrm{A}, \mathrm{Fe}$, folate and vitamin $\mathrm{C}$ is a routine procedure of the maternity hospital and focuses mainly on the prevention or treatment of gestational anaemia. The amounts supplemented conform to the safe total levels of vitamin A for the women's reproductive age ${ }^{(25)}$.

\section{Variables analysed}

The gestational XN outcome was assessed using an interview that was standardized by the $\mathrm{WHO}^{(26)}$ and confirmed by biochemical assay (serum retinol, as reported by Saunders et al. $)^{(27)}$. The interview included the following questions: (i) 'Do you have difficulty seeing during the day?' (ii) 'Do you have difficulty seeing in low light or at night?' (iii) 'Do you have night blindness?' Gestational XN was considered when the woman answered 'no' to the first question and 'yes' to either the second or third question, or both. If the pregnant woman presented with any vision problem, her vision capacity was evaluated with glasses or contact lenses to correct the vision problem. The interview was conducted using simple language and examples of places with low light ${ }^{(26)}$.

Socio-economic and environmental factors, prenatal care data and biological, clinical and obstetric data were the independent variables tested. The theoretical hierarchical model proposed is shown in Fig. 1. The choice of possible predictive risk factors of gestational XN was based on data from the literature ${ }^{(8,27-30)}$.

To characterize socio-economic status during prenatal care as well as the biological, obstetric and clinical data of the pregnant women, variables that are part of the prenatal care protocol of the maternity hospital were selected and obtained by searching the medical records.

\section{Anthropometric measurements and pregnancy complication assessments}

The following anthropometric assessments were performed: weight before pregnancy reported or measured before the 13th week of gestation; and height and weight before delivery or those recorded in the last prenatal care visit before delivery. The pre-pregnancy BMI was calculated and evaluated according to the cut-offs proposed by the Institute of Medicine ${ }^{(31)}$. The total pregnancy weight gain was estimated by subtracting the pre-pregnancy weight from the weight before delivery or that recorded in the last prenatal care visit occurring no later than $7 \mathrm{~d}$ before delivery. The adequacy of pregnancy weight gain was classified as adequate weight gain (as recommended) and inadequate weight gain (below or above the recommended) ${ }^{(31)}$.

The following pregnancy complications were considered: gestational diabetes, gestational hypertension, urinary infection and others, according to the patients' medical records and in agreement with the recommendations of the Brazilian Ministry of Health ${ }^{(32)}$. Anaemia was diagnosed when the woman's Hb level was below $110 \mathrm{~g} / \mathrm{l}^{(32)}$.

\section{Hierarchical model}

The variables selected as described below were grouped into three levels (blocks). The 'distal level' comprised the following socio-economic variables: maternal age (20-34 years or $\geq 35$ years), marital status (living with a partner or living without a partner), skin colour (white or non-white), education (incomplete primary education or complete primary education), occupation (homemaker or working outside the home) and per capita household income in minimum wages (MW; $<1 \mathrm{MW}, 1$ to $<2 \mathrm{MW}$ or $\geq 2 \mathrm{MW}$ ); and the following environmental variables: residence (South Zone of Rio de Janeiro or others) and number of household members ( $\geq 5$ members, 3 or 4 members or $\leq 2$ members).

The 'intermediate level' comprised the following variables of access and quality of prenatal care: number of prenatal visits ( $<6$ or $\geq 6$ ), number of visits with a nutritionist during prenatal care $(<4$ or $\geq 4)$, gestational age at first visit with the nutritionist during prenatal care $(<14$ th week of gestation or $\geq 14$ th week of gestation) and study group (GI or GII).

The 'proximal level' comprised the following variables associated with the women: obstetric characteristics, i.e. history of all-cause abortion (yes or no) and inter-gestational interval ( $<24$ months or $\geq 24$ months); biological characteristics, i.e. pre-pregnancy nutritional status (underweight/ normal weight or overweight/obesity) and adequacy of gestational weight gain (below or adequate and above); and clinical characteristics, i.e. dietary supplementation during pregnancy (yes or no), pregnancy complications (yes or no) and anaemia in the first or second trimester of pregnancy (yes or no).

\section{Statistical analysis}

Measures of central tendency, as well as the means and standard deviations of continuous variables, were calculated to describe the sample. In the data analysis, associations between possible determinants of XN during pregnancy were initially tested through bivariate analysis with all 


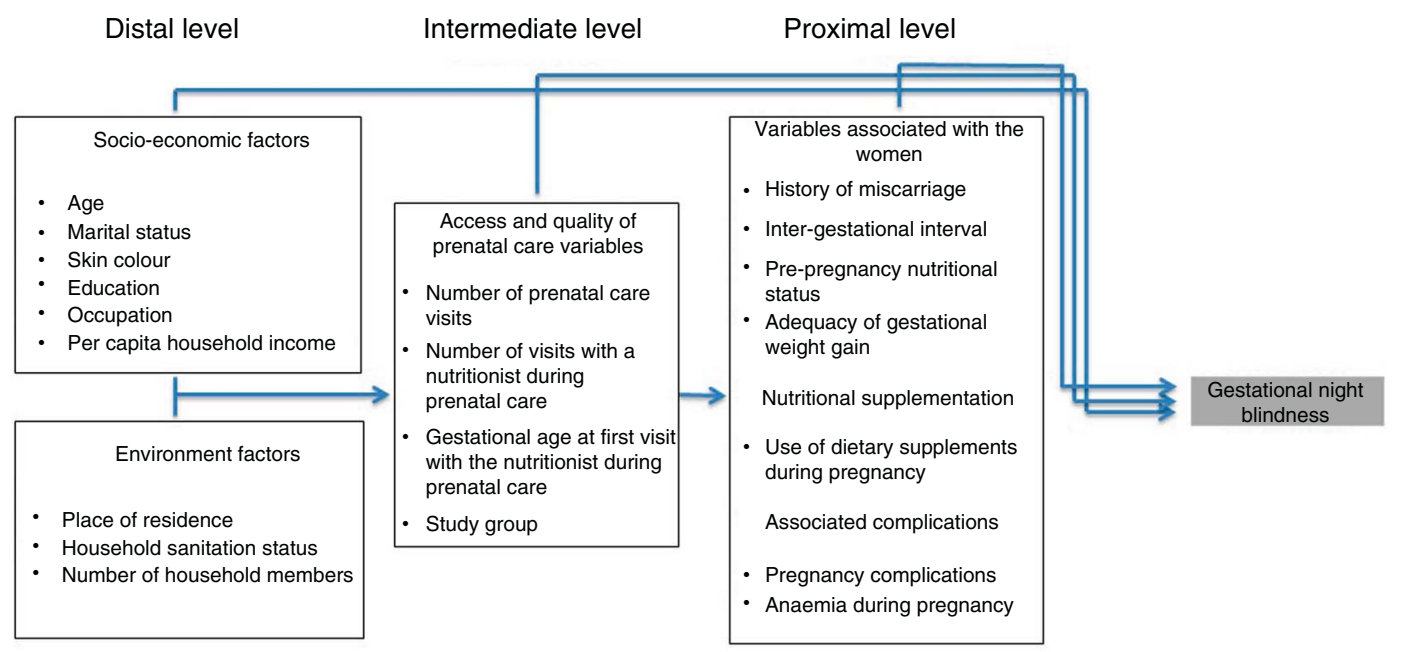

Fig. 1 Conceptual hierarchical model of the process of determining gestational night blindness in adult women seen in a public maternity hospital in Rio de Janeiro, RJ, Brazil

variables of each hierarchical level (distal, intermediate and proximal levels). Crude odds ratios were estimated with 95\% confidence intervals using simple logistic regression.

To construct the final model, the variables were added into the model step by step, considering the hierarchical levels: distal, intermediate and proximal. A $P$ value of $<0.25$ obtained in the bivariate analysis was adopted as the criterion to include variables in the model. To fit the model into the hierarchical levels, variables with $P<0.05$ remained in the model at each level of analysis.

In the final model, the adjusted odds ratios were estimated with their respective $95 \%$ confidence intervals using a hierarchical logistic regression, and the results were expressed as the crude and adjusted odds ratio according to each hierarchical level. The statistical software package IBM SPSS Statistics version 20 was used to perform the analysis.

\section{Sample size}

Because the number of women with available information for the present analysis was smaller than the total sample of the original study, post hoc calculations were performed. Assuming a $10 \%$ prevalence of gestational XN and a significance level of $5 \%$ and $80 \%$ power, the sample size of the current study (606 women) was able to detect differences of at least $6 \%$ in the prevalence of gestational XN between the groups.

\section{Ethical issues}

The research projects that generated the databases were in agreement with the guidelines of Resolution 196/96 of the Brazilian National Health Council (signatory of the Declaration of Helsinki) and were approved by the Ethics Committee of the Maternity Hospital, Federal University of Rio de Janeiro (Opinion no. 35/04, dated 25/02/2002) and the National School of Public Health, Oswaldo Cruz Foundation (Opinion no. 75/02, dated 04/09/2002).
All participants went through an informed consent process and signed an informed consent form.

\section{Results}

The prevalence of gestational XN observed in the study was 9.9\%. Only twenty-three women were able to accurately report at which gestational age the ocular symptom started; for these women, it began on average during week 18 (SD 8.09) of pregnancy, with minimum and maximum gestational ages of 8 and 35 weeks, respectively. The mean maternal age was 27.6 (SD 5.2) years. Among the pregnant women analysed in the study, 59.2\% lived in the South Zone of Rio de Janeiro; $78.4 \%$ were living with a partner; $63.2 \%$ were non-white (black or mulatto/mixed); $70.3 \%$ had completed primary education (Table 1); and $88.4 \%$ attended six or more prenatal visits (Table 2).

The bivariate analysis revealed possible determinants of gestational $\mathrm{XN}$ within the three hierarchical levels (Tables 1-3). With respect to socio-economic factors (distal level), place of residence $(P=0.009)$, skin colour $(P=0.219)$, per capita household income $(P<0.05)$ and number of household members $(P<0 \cdot 05)$ were associated with gestational XN.

A greater chance of gestational XN was observed among women who lived outside the South Zone of Rio de Janeiro (OR $=2.044 ; 95 \%$ CI 1.193, 3.504) or in a home with a large number of members ( $\geq 5$ members: OR $=2.751 ; 95 \%$ CI 1.284, 5.894; Table 1). Pregnant women living in the South Zone of Rio de Janeiro had better living conditions (higher per capita household income and fewer household members). Higher per capita household income represented a protective factor against gestational XN (1 to <2 MW: OR=0.483; $95 \%$ CI $0 \cdot 248$, 0.940; $\geq 2$ MW: OR=0.427; $95 \%$ CI 0.202, 0.802; Table 1 ). 
Table 1 Socio-economic determinants (distal) of gestational night blindness $(\mathrm{XN})$ in adult women seen in a public maternity hospital in Rio de Janeiro, RJ, Brazil (1999-2008)

\begin{tabular}{|c|c|c|c|c|c|c|}
\hline \multirow[b]{2}{*}{ Variable } & \multirow{2}{*}{$\underset{n}{\text { Sample }}$} & \multicolumn{2}{|c|}{ Gestational XN } & \multirow[b]{2}{*}{ OR } & \multirow[b]{2}{*}{$95 \% \mathrm{Cl}$} & \multirow[b]{2}{*}{$P$} \\
\hline & & $n$ & $\%$ & & & \\
\hline Place of residence & 606 & & & & & 0.009 \\
\hline Others & 247 & 34 & 13.8 & 2.044 & $1 \cdot 193,3.504$ & \\
\hline Southern & 359 & 26 & $7 \cdot 2$ & 1.000 & Ref. & \\
\hline Age (years) & 605 & & & & & 0.845 \\
\hline $20-34$ & 540 & 54 & 10.0 & 1.093 & $0.451,2.649$ & \\
\hline$\geq 35$ & 65 & 6 & $9 \cdot 2$ & 1.000 & Ref. & \\
\hline Marital status & 578 & & & & & 0.952 \\
\hline Living without a partner & 127 & 47 & $10 \cdot 4$ & 1.020 & $0.533,1.951$ & \\
\hline Married/living with a partner & 451 & 13 & $10 \cdot 2$ & 1.000 & Ref. & \\
\hline Skin colour & 511 & & & & & 0.219 \\
\hline White & 188 & 26 & 13.8 & 1.410 & $0.815,2.442$ & \\
\hline Others & 323 & 33 & 10.2 & 1.000 & Ref. & \\
\hline Schooling & 602 & & & & & 0.962 \\
\hline Incomplete primary education & 179 & 18 & $10 \cdot 1$ & 1.014 & $0.567,1.815$ & \\
\hline Complete primary education & 423 & 42 & 9.9 & 1.000 & Ref. & \\
\hline Occupation & 597 & & & & & 0.578 \\
\hline Housewife & 190 & 21 & $11 \cdot 1$ & $1 \cdot 173$ & $0.669,2.055$ & \\
\hline Working from home & 407 & 39 & 9.6 & 1.000 & Ref. & \\
\hline Per capita household income (MW) & 445 & & & & & \\
\hline$<1$ & 146 & 26 & $17 \cdot 8$ & 1.000 & Ref. & \\
\hline 1 to $<2$ & 169 & 16 & 9.5 & 0.483 & $0.248,0.940$ & 0.032 \\
\hline$\geq 2$ & 130 & 11 & 8.5 & 0.427 & $0.202,0.802$ & 0.026 \\
\hline No. of household members & 503 & & & & & \\
\hline$\geq 5$ & 76 & 15 & $19 \cdot 7$ & $2 \cdot 751$ & $1 \cdot 284,5.894$ & 0.009 \\
\hline 3 or 4 & 232 & 28 & $12 \cdot 1$ & 1.792 & $0.899,3.569$ & 0.193 \\
\hline$\leq 2$ & 195 & 16 & 8.2 & 1.000 & Ref. & - \\
\hline
\end{tabular}

MW, minimum wage; Ref., reference category.

Table 2 Prenatal care-related determinants (intermediate) of gestational night blindness $(\mathrm{XN})$ in adult women seen in a public maternity hospital in Rio de Janeiro, RJ, Brazil (1999-2008)

\begin{tabular}{|c|c|c|c|c|c|c|}
\hline \multirow[b]{2}{*}{ Variable } & \multirow{2}{*}{$\begin{array}{c}\text { Sample } \\
n\end{array}$} & \multicolumn{2}{|c|}{ Gestational XN } & \multirow[b]{2}{*}{ OR } & \multirow[b]{2}{*}{$95 \% \mathrm{Cl}$} & \multirow[b]{2}{*}{$P$} \\
\hline & & $n$ & $\%$ & & & \\
\hline No. of prenatal visits & 604 & & & & & 0.001 \\
\hline$<6$ & 70 & 15 & 21.4 & 2.964 & $1.551,5.662$ & \\
\hline$\geq 6$ & 534 & 45 & 8.4 & 1.000 & Ref. & \\
\hline No. of prenatal nutritional visits & 606 & & & & & 0.008 \\
\hline$<4$ & 402 & 49 & $12 \cdot 2$ & 2.453 & $1.237,4.793$ & \\
\hline$\geq 4$ & 204 & 11 & 5.4 & 1.000 & Ref. & \\
\hline $\mathrm{GA}$ at first prenatal nutritional visit & 378 & & & & & 0.165 \\
\hline$<14$ th gestational week & 120 & 8 & $6 \cdot 7$ & 1.976 & $0.743,5.256$ & \\
\hline$\geq 14$ th gestational week & 258 & 9 & 3.5 & 1.000 & Ref. & \\
\hline Study group & 606 & & & & & 0.001 \\
\hline Gl & 225 & 43 & $19 \cdot 1$ & $5 \cdot 059$ & $2 \cdot 807,9 \cdot 117$ & \\
\hline Gll & 381 & 17 & 4.5 & 1.000 & Ref. & \\
\hline
\end{tabular}

GA, gestational age; GI, group I, pregnant women seen in the hospital from 1999 to 2001; GIl, group II, pregnant women seen in the hospital from 2005 to 2008 ; Ref., reference category.

All variables included in the intermediate level met the criteria for entry into the multivariate analysis, and the prevalence of $\mathrm{XN}$ decreased fivefold in the group of pregnant women who had access to adequate nutritional assistance (GII; Table 2).

Considering that information about gestational age at the first visit with the nutritionist during prenatal care was obtained only from 378 pregnant women, it was assumed that the variable study group would be a proxy for the quality of nutritional assistance offered to the pregnant women (Table 3).

The proximal-level variables selected for the multivariate analysis were: history of abortion $(P=0 \cdot 217)$, adequacy of gestational weight gain $(P=0 \cdot 104)$ and anaemia in the first or second trimester of pregnancy $(P=0.003)$. The crude and adjusted odds ratios for the 
Table 3 Maternal-related determinants (biological and obstetric characteristics, proximal) of gestational night blindness (XN) in adult women seen in a public maternity hospital in Rio de Janeiro, RJ, Brazil (1999-2008)

\begin{tabular}{|c|c|c|c|c|c|c|}
\hline \multirow[b]{2}{*}{ Variables } & \multirow{2}{*}{$\begin{array}{c}\text { Sample } \\
n\end{array}$} & \multicolumn{2}{|c|}{ Gestational XN } & \multirow[b]{2}{*}{ OR } & \multirow[b]{2}{*}{$95 \% \mathrm{Cl}$} & \multirow[b]{2}{*}{$P$} \\
\hline & & $n$ & $\%$ & & & \\
\hline History of abortion & 606 & & & & & 0.217 \\
\hline Yes & 180 & 26 & 14.4 & 1.468 & $0.798,2.791$ & \\
\hline No & 426 & 34 & 8.0 & 1.000 & Ref. & \\
\hline Inter-gestational range & 241 & & & & & 0.845 \\
\hline$<24$ months & 71 & 12 & $16 \cdot 9$ & 1.077 & $0.512,2.268$ & \\
\hline$\geq 24$ months & 170 & 27 & $15 \cdot 9$ & 1.000 & Ref. & \\
\hline Pre-pregnancy nutritional status & 596 & & & & & 0.354 \\
\hline Underweight/normal & 413 & 44 & $10 \cdot 7$ & 1.336 & $0.723,2.467$ & \\
\hline Overweight/obesity & 183 & 15 & 8.2 & 1.000 & Ref. & \\
\hline Adequacy of gestational weight gain & 589 & & & & & 0.104 \\
\hline Below & 151 & 20 & $13 \cdot 2$ & 1.607 & $0.903,2.860$ & \\
\hline Appropriate and above & 438 & 38 & 8.7 & 1.000 & Ref. & \\
\hline Supplementation use in pregnancy & 373 & & & & & 0.589 \\
\hline No & 6 & 0 & 0.0 & 1.049 & $1.025,1.072$ & \\
\hline Yes & 367 & 17 & 4.6 & 1.000 & Ref. & \\
\hline First- or second-trimester anaemia & 498 & & & & & 0.003 \\
\hline Yes & 131 & 12 & $9 \cdot 2$ & $3 \cdot 250$ & $1 \cdot 487,7 \cdot 127$ & \\
\hline No & 367 & 16 & $4 . \overline{4}$ & 1.000 & Ref. & \\
\hline Pregnancy intercurrences & 606 & & & & & 0.593 \\
\hline No & 500 & 51 & $10 \cdot 2$ & 1.224 & $0.583,2.571$ & \\
\hline Yes & 106 & 9 & 8.5 & 1.000 & Ref. & \\
\hline
\end{tabular}

Ref., reference category.

proximal-level variables and their corresponding $95 \%$ confidence intervals obtained in the hierarchical model are shown in Tables 3 and 4 .

The final model revealed that not living in the South Zone of Rio de Janeiro (distal level: adjusted $\mathrm{OR}=1 \cdot 846$; $95 \%$ CI 1.002, 3.401), belonging to GI (intermediate level: adjusted $\mathrm{OR}=2 \cdot 183 ; 95 \% \mathrm{CI} 1 \cdot 066,4 \cdot 471)$, history of abortion (proximal level: adjusted $\mathrm{OR}=2 \cdot 840 ; 95 \% \mathrm{CI}$ $1 \cdot 134,7 \cdot 115)$ and an anaemia diagnosis in the first or second trimester of pregnancy (proximal level: adjusted $\mathrm{OR}=3.776 ; 95 \% \mathrm{CI} 1.579$, 9.029) were the determinants of gestational XN (Table 4).

\section{Discussion}

The present study identifies determinants of gestational $\mathrm{XN}$ in adult pregnant women residing in the city of Rio de Janeiro. These determinants were zone of residence, access to adequate nutritional assistance, history of all-cause abortion and gestational anaemia, which is another common nutritional deficiency among pregnant women. The environmental conditions represented by place of residence (distal level) as well as the nutritional monitoring represented by the variable study group (intermediate level) were associated with the chance of developing gestational XN. A history of abortion and a diagnosis of anaemia (proximal level) were associated with gestational $\mathrm{XN}$ regardless of socio-economic conditions, prenatal care conditions and maternal anthropometric characteristics.
The hierarchical multivariate model was useful in the present study because it allowed for the identification of the determinants of gestational $\mathrm{XN}$ for the first time in the national literature. The current analysis elucidates associations between variables still poorly investigated in studies about XN in Brazilian pregnant women, in addition to identifying the periods during which they have greater impact ${ }^{(33)}$.

The measured prevalence of gestational XN was similar to values found in other national studies but higher than the value reported by Santos et $a .^{(34)}$, who studied pregnant women receiving care in health-care units in the city of Diamantina, Minas Gerais state, a region considered at higher risk for VAD, where a prevalence of $8.7 \%$ was observed $^{(34)}$. Another Brazilian study conducted with adult pregnant women in the same hospital analysed in the present study revealed that $18.0 \%$ had XN during pregnancy over the period 1999-2001 ${ }^{(27)}$. After the implementation of a nutritional intervention into the prenatal care programme in this hospital (an increase in the number of visits with a nutritionist that started concomitantly with prenatal care and the adoption of practices recommended to prevent and treat VAD), the prevalence of gestational $\mathrm{XN}$ among adult pregnant women decreased from $19 \cdot 1 \%$ to $4.5 \%{ }^{(23)}$.

These findings corroborate the results of the present study, as the final model demonstrated that the changes adopted over the years in the routine prenatal nutritional assistance programme of the studied maternity hospital were beneficial in reducing gestational XN. The systematic nutritional assistance practised in this 
Table 4 Final hierarchical model with crude and adjusted odds ratios, and $95 \%$ confidence intervals, to estimate the determinants of gestational night blindness in adult women seen in a public maternity hospital in Rio de Janeiro, RJ, Brazil (1999-2008)

\begin{tabular}{|c|c|c|c|c|c|c|}
\hline & $P$ & OR crude & $95 \% \mathrm{Cl}$ & $P$ & OR adjusted & $95 \% \mathrm{Cl}$ \\
\hline \multicolumn{7}{|l|}{ Distal level } \\
\hline \multicolumn{7}{|l|}{ Place of residence } \\
\hline Others & & 2.044 & $1 \cdot 193,3.504$ & & 1.846 & $1.002,3.401$ \\
\hline Southern & 0.009 & 1.000 & Ref. & 0.049 & 1.000 & Ref. \\
\hline \multicolumn{7}{|l|}{ Skin colour } \\
\hline White & & 1.410 & $0.815,2.442$ & & $1 \cdot 251$ & $0.682,2.294$ \\
\hline Others & 0.219 & 1.000 & Ref. & 0.470 & 1.000 & Ref. \\
\hline \multicolumn{7}{|l|}{ No. of household members } \\
\hline$\geq 5$ & 0.009 & $2 \cdot 751$ & $1 \cdot 284,5.894$ & $0 \cdot 216$ & 1.792 & $0.712,4.513$ \\
\hline 3 or 4 & 0.193 & 1.792 & $0.899,3.569$ & 0.503 & 1.295 & $0.608,2.760$ \\
\hline$\leq 2$ & & 1.000 & Ref. & 0.462 & 1.000 & Ref. \\
\hline \multicolumn{7}{|c|}{ Per capita household income (MW) } \\
\hline$\geq 2$ & 0.026 & 0.427 & $0.202,0.802$ & 0.109 & 0.510 & $0.224,1.162$ \\
\hline 1 to $<2$ & 0.032 & 0.483 & $0.248,0.940$ & 0.069 & 0.512 & $0.249,1.053$ \\
\hline$<1$ & & 1.000 & Ref. & 0.124 & 1.000 & Ref. \\
\hline \multicolumn{7}{|l|}{ Intermediate level ${ }^{*}$} \\
\hline \multicolumn{7}{|l|}{ No. of prenatal visits } \\
\hline$<6$ & & 2.964 & $1.551,5.662$ & & $1 \cdot 760$ & $0.802,3.866$ \\
\hline$\geq 6$ & 0.001 & 1.000 & Ref. & 0.159 & 1.000 & Ref. \\
\hline \multicolumn{7}{|l|}{ Study group } \\
\hline Gl & & 5.059 & $2 \cdot 807,9 \cdot 117$ & & $2 \cdot 183$ & $1.066,4.471$ \\
\hline Gll & 0.001 & 1.000 & Ref. & 0.033 & 1.000 & Ref. \\
\hline \multicolumn{7}{|l|}{ Proximal level† } \\
\hline \multicolumn{7}{|l|}{ History of abortion } \\
\hline Yes & & 1.468 & $0.798,2.701$ & & $2 \cdot 840$ & $1 \cdot 134,7 \cdot 115$ \\
\hline No & 0.217 & 1.000 & Ref. & 0.026 & 1.000 & Ref. \\
\hline \multicolumn{7}{|c|}{ Adequacy of gestational weight gain } \\
\hline Below & & 1.607 & $0.903,2.860$ & & $1 \cdot 110$ & $0.431,2.860$ \\
\hline Appropriate and above & 0.107 & 1.000 & Ref. & 0.829 & 1.000 & Ref. \\
\hline \multicolumn{7}{|c|}{ First- or second-trimester anaemia } \\
\hline Yes & & $3 \cdot 256$ & $1 \cdot 487,7 \cdot 127$ & & 3.776 & $1.579,9.029$ \\
\hline No & 0.003 & 1.000 & - & 0.003 & 1.000 & - \\
\hline
\end{tabular}

MW, minimum wage; GI, group I, pregnant women seen in the hospital from 1999 to 2001; GII, group II, pregnant women seen in the hospital from 2005 to 2008 ; Ref., reference category.

*Adjusted for living place.

†Adjusted for study group.

hospital included an earlier initiation of monitoring by a nutritionist, guidance regarding a healthy and adequate diet to meet the increased nutritional needs during pregnancy associated with the classic strategies recommended for combating VAD, such as encouragement to consume foods rich in vitamin $\mathrm{A}$ and fortified foods, and adherence to the supplementation scheme prescribed during pregnancy $(35,36)$. The consumption of beef liver once weekly (lunch or dinner) and of other animal and plant sources of vitamin A was promoted during the visits. This is similar to recommendations described in studies of adult ${ }^{(37)}$ and adolescent ${ }^{(38)}$ pregnant women, as well as other strategies aimed at reducing high-impact deficiencies like anaemia $^{(23)}$.

The nutritional assistance practised in this maternity hospital can be adapted to other levels of prenatal care. In addition, other health-care professionals can be made aware of and trained to assess for gestational $\mathrm{XN}$ with the application of the standardized interview, and to implement the aforementioned strategies for combating VAD. This nutritional intervention can contribute to the reduction of gestational $\mathrm{XN}$ and improve maternal/child health, in addition to helping to reduce maternal mortality ${ }^{(5)}$.

The importance of prenatal care to detect and treat nutritional deficiencies in pregnant women has been emphasized by the WHO since $1999^{(5)}$. In a 2011 committee statement, it was noted that many pregnant women present with nutritional deficiencies, especially anaemia, VAD and iodine deficiency, during early pregnancy. The committee recognized that these deficiencies can affect birth weight and chances of survival, and that inadequate intake of vitamin $\mathrm{A}$ increases the risk of gestational $\mathrm{XN}^{(36)}$.

The high prevalence of gestational XN (9.9\%) found in the present study reflects the vulnerability of women of reproductive age in the city of Rio de Janeiro to VAD. This finding aligns with the results from the last Children and Women National Demographic and Health Survey (Pesquisa Nacional de Demografia e Saúde da Criança $e$ da Mulher (PNDS), 2006) ${ }^{(3)}$, which, based on serum retinol concentrations, demonstrated that $15.5 \%$ of women from the Southeast region of Brazil presented with $\mathrm{VAD}$, the highest value observed in the country ${ }^{(3)}$. These data suggest that VAD must be monitored in women of reproductive age and during pregnancy because it is 
known that women who begin a pregnancy with low stores of vitamin A and maintain a diet poor in this nutrient during pregnancy have a greater chance of developing $\mathrm{VAD}$ and gestational $\mathrm{XN}$, particularly during the third trimester ${ }^{(25,36)}$. Consequently, both mother and child will be exposed to the adverse effects of this deficiency.

Recent studies suggest that vitamin A supplementation in women of reproductive age may contribute to reduced mortality only in populations that present a high prevalence of $\operatorname{VAD}(>10 \%$ gestational $\mathrm{XN})$ and high maternal mortality rates (>500 deaths per 100000 live births) ${ }^{(39)}$. These data reinforce the notion that other strategies, such as those used in the present study, must be designed and implemented in order to improve the nutritional status of pregnant women and women of reproductive age. Because supplementation with vitamin A has a short-term impact, after this period other interventions must be implemented to maintain adequate levels of this nutrient, including, for example, nutritional assistance, food fortification with vitamin A and dietary diversification ${ }^{(1,36)}$.

Due to higher physiological demand for vitamin A during pregnancy, even pregnant women presenting with subclinical VAD can develop gestational $\mathrm{XN}$, which is known to be associated with other biochemical indicators of $\mathrm{VAD}^{(26)}$. Among the negative consequences to the health of pregnant women are higher incidence of preterm birth, complications such as gestational hypertension, increased risk of maternal mortality caused by respiratory infection and other infections ${ }^{(7)}$, diarrhaea ${ }^{(40)}$ and increased risk of postpartum maternal mortality ${ }^{(7,41)}$. The presence of gestational $\mathrm{XN}$ also increases the risk of low birth weight and detracts from the health of the newborn in early childhood, as it is associated with an increased risk of diarrhoea, dysentery, acute respiratory infections and poor growth measurements at 6 months of life ${ }^{(42)}$.

The presence of gestational $\mathrm{XN}$ also increases the risk of neonatal death in the first 6 months of life ${ }^{(8,9)}$. The negative impact of maternal VAD on the health of the child during childhood and even adolescence was described in a study conducted in Nepal. In the latter study, the authors demonstrated in a population with chronic VAD that supplementation with vitamin A before, during and after pregnancy resulted in improved lung function in children at 9-13 years of age ${ }^{(43)}$.

The present study demonstrates that place of residence is one of the socio-economic determinants of gestational $\mathrm{XN}$. A higher percentage of women with better living conditions (higher per capita household income and fewer household members) live in the South Zone of Rio de Janeiro. This association suggests that this group of women have better access to a healthy diet and consequently to foods rich in vitamin A. These women are also less exposed to infections and parasites, which can be one of the factors associated with VAD ${ }^{(18)}$.

A history of all-cause abortion is another determinant of gestational XN. Adjusted odds ratios were higher in the final model because the sample size used in the final analysis was smaller ( $n$ 340), which revealed a greater difference between women with and women without a history of abortion. The association between history of abortion and gestational VAD was previously described by Simsek et $a l^{(44)}$, who showed lower serum levels of vitamin A among women with a history of abortion. In another study, Neela and Raman ${ }^{(45)}$ reported increased serum retinol levels among women with a history of abortion. An association between history of abortion and a short inter-gestational interval, which can contribute to the depletion of maternal reserves of vitamin $\mathrm{A}$ and is considered a trigger for gestational $\mathrm{XN}$, has also been described ${ }^{(21)}$.

Maconochie et al. ${ }^{(46)}$ suggest that abortion is associated with nutritional status and diet. The authors offer that a low pre-pregnancy BMI and the low consumption of micronutrient-rich foods (fruits and vegetables) are some factors associated with this outcome. This information is of particular importance for women from developing countries, where the main dietary sources of vitamin A and other micronutrients are vegetables ${ }^{(47)}$. Therefore, adequate dietary intake, as well as the correct intake of vitamin supplements, may have some impact in reducing abortion ${ }^{(46)}$.

Anaemia is another important nutritional deficiency in Brazil $^{(3)}$ and the present study demonstrates that it is a risk factor for gestational XN. The Brazilian Ministry of Health estimates that the prevalence of gestational anaemia is $50 \%{ }^{(12)}$ and it is associated with $20 \%$ of total maternal deaths ${ }^{(17)}$. Some studies report that in communities where anaemia is prevalent among pregnant women, VAD should also be assessed ${ }^{(3,10,11)}$.

A study performed in Recife, Brazil, revealed anaemia and VAD in $65.3 \%$ and $25.0 \%$ of postpartum adult and adolescent women, respectively ${ }^{(10)}$. A population-based case-control study conducted in Nepal also demonstrated that pregnant women who had gestational $\mathrm{XN}$ were more likely to be anaemic, malnourished and to consume a diet low in vitamin $\mathrm{A}^{(8)}$.

The association between these two nutritional deficiencies remains inconclusive. It is believed that $\mathrm{VAD}$ can impair the absorption, transport and storage of $\mathrm{Fe}^{(11,48)}$. Several hypotheses have been proposed, including the potential action of vitamin $\mathrm{A}$ in the mobilization of hepatic Fe stores, increased erythropoiesis, decreased 'anaemia of inflammation' through increased circulating $\mathrm{Fe}$ via reduction of infection and increased absorption of $\mathrm{Fe}^{(11)}$.

Brazil has guidelines in place for Fe supplementation during pregnancy ${ }^{(49)}$, as well as fortification of flour with Fe and folic acid to prevent and treat anaemia. The benefit of flour fortification in reducing gestational anaemia in pregnant women has been described in Rio de Janeiro ${ }^{(50)}$. Similar to the case with anaemia, VAD among pregnant women should be a focus of nationwide health programmes as a measure to promote maternal and child health. As observed in the present study, prenatal nutritional monitoring associated with routine prenatal 
care, including encouragement to use vitamin A supplementation, was one of the protective factors against gestational XN. The $\mathrm{WHO}^{(36)}$ recommends weekly or daily vitamin A supplementation for pregnant women living in areas where $\mathrm{VAD}$ is a severe public health problem (population prevalence of $\mathrm{XN} \geq 5 \%$ in pregnant women or in children aged 24-59 months) to prevent ocular symptoms ${ }^{(36)}$, in addition to other strategies such as dietary diversification, education and encouragement regarding healthy eating habits, and the use of fortified foods.

The fact that among the sixty women diagnosed with gestational XN, only twenty-three were able to accurately report the onset of ocular symptoms during pregnancy was a limitation of the present study. In addition, lack of data about adherence to vitamin A supplementation and the dose of vitamin A consumed via both supplementation and regular diet were also limiting factors. Such information would be instructive and allow for comparison of the present results with those from other studies.

\section{Conclusion}

The present study reveals a significant prevalence (9.9\%) of gestational XN among adult pregnant women in Rio de Janeiro. The determinants were socio-economic status (specifically, place of residence); study group (a proxy for the presence and quality of prenatal nutritional assistance); and history of abortion and presence of anaemia in the first and second trimesters of pregnancy.

These results indicate that VAD should be assessed for during routine prenatal care, and that gestational $\mathrm{XN}$ should be assessed for in all pregnant women, especially those living in deprived areas of the city of Rio de Janeiro and those with a history of abortion or who have been diagnosed with gestational anaemia. In addition, nutritional monitoring during pregnancy may have a positive impact on the prevention and control of gestational $\mathrm{XN}$. Therefore, nutritional monitoring should be initiated concurrently with the beginning of prenatal care and continued throughout the entire gestational period.

These data also suggest that in the city of Rio de Janeiro, despite it not being a region classically considered as at higher risk, VAD among women of reproductive age and during the pregnancy/postpartum period may be an underestimated problem. Further investigation at other maternity hospitals and health-care units is warranted, with adequate prevention and control of this nutritional deficiency as needed, in order to head off serious consequences for the health of both mother and child.

\section{Acknowledgements}

Financial support: This study was financially supported by the National Counsel for Technological and Scientific
Development (Conselho Nacional de Desenvolvimento Científico e Tecnológico (CNPq)) (notice 51/2005, which funded the project entitled 'Assessment of the impact of prenatal nutritional assistance on obstetric outcome' (login sigma/UFRJ 12127)) and by CNPq Research Productivity (RP) Fellowships to C.S. and M.d.C.L. Conflict of interest: None. Authorship: C.S. and M.d.C.L. designed and planned the study; C.S. and P.d.C.P. collected the data; C.S., M.d.C.L. and A.O.C.S. analysed the data; C.S., M.d.C.L., P.A.R.N., P.d.C.P. and L.B.d.G. participated in the writing and revision of the final version of the manuscript. Ethics of buman subject participation: The study was designed according to Resolution 196/96 of the Brazilian National Health Council/Ministry of Health, which is a signatory of the Declaration of Helsinki.

\section{References}

1. World Health Organization (2009) Global Relevance of Vitamin A Deficiency in Populations at Risk 1995-2005. WHO Global Database on Vitamin A Deficiency. Geneva: WHO.

2. Organização Mundial da Saúde (2013) Diretriz: Suplementação de Vitamina em Mulberes no Pós-parto. Genebra: OMS.

3. Brasil, Ministério da Saúde (2009) PNDS 2006: Pesquisa Nacional de Demografia e Saúde da Criança e da Mulber. Brasília: MS

4. World Health Organization (2006) Vitamin and Mineral Nutrition Information System (VMNIS). WHO Global Database on Vitamin A Deficiency. The Vitamin A Deficiency database includes data by country based on xerophthalmia and/or serum or plasma retinol concentration. Brazil. http:// www.who.int/vmnis/database/vitamina/countries/en/

5. Organización Mundial de la Salud (1999) Reducción de la Mortalidad Materna. Ginebra: OMS/FNUAP/UNICEF/BM.

6. Campos LF, Saunders C, Ramalho A et al. (2008) Níveis de retinol e carotenóides séricos e intercorrências gestacionais em puérperas. Rev Nutr 21, 623-632.

7. Christian P, West KP Jr, Khatry SK et al. (2000) Night blindness during pregnancy and subsequent mortality among women in Nepal: effects of vitamin $A$ and $\beta$-carotene supplementation. Am J Epidemiol 152, 542-547.

8. Christian P, West KP Jr, Khatry SK et al. (1998) Night blindness of pregnancy in rural Nepal - nutritional and health risks. Int J Epidemiol 27, 231-237.

9. Christian P, West KP Jr, Khatry SK et al. (2001) Maternal night blindness increases risk of mortality in the first 6 months of life among infants in Nepal. J Nutr 131, 1510-1512.

10. Lopes RE, Ramos KS, Bressani CC et al. (2006) Prevalência de anemia e hipovitaminose A em puérperas do Centro de Atenção à Mulher do Instituto Materno Infantil Prof. Fernando Figueira, IMIP: um estudo piloto. Rev Bras Saude Materno Infant 6, Suppl. 1, S63-S68.

11. Thorne-Lyman AL \& Fawzi WW (2012) Vitamin A and carotenoids during pregnancy and maternal, neonatal and infant health outcomes: a systematic review and meta-analysis. Paediatr Perinat Epidemiol 26, 36-54.

12. Brasil, Ministério da Saúde, Secretaria de Atenção à Saúde, Departamento de Ações Programáticas Estratégicas (2012) Gestação de Alto Risco: Manual Técnico, 5th ed. Brasília: MS

13. International Vitamin A Consultative Group (2002) Maternal Night Blindness: A New Indicator of Vitamin A Deficiency. Washington, DC: IVACG. 
14. Christian P (2002) Recommendations for indicators: Night blindness during pregnancy - a simple tool to assess vitamin A deficiency in a population. J Nutr 132, 9 Suppl., 2884S-288S.

15. West KP Jr \& Mehra S (2010) Vitamin A intake and status in populations facing economic stress. J Nutr 140, issue 1, 201S-207S.

16. Akhtar S, Ahmed A, Randhawa MA et al. (2013) Prevalence of vitamin A deficiency in South Asia: causes, outcomes, and possible remedies. J Health Popul Nutr 31, 413-423.

17. Micronutrient Initiative (2009) Investing in the Future. A United Call to Action on Vitamin and Mineral Deficiencies. Global Reports 2009. Ottawa: Micronutrient Initiative.

18. Pandey S, Lin Y, Collier-Tenison S et al. (2012) Social factors determining the experience of blindness among pregnant women in developing countries: the case of India. Health Soc Work 37, 157-169.

19. Gebreselassie SG, Gase FE \& Deressa UM (2013) Prevalence and correlates of prenatal vitamin A deficiency in Rural Sidama, Southern Ethiopia. J Health Popul Nutr 31, 185-194.

20. Abebe H, Abebe Y, Loha E et al. (2014) Consumption of vitamin A rich food and dark adaptation threshold of pregnant women at Damot Sore District, Wolayita, Southern Ethiopia. Ethiop J Health Sci 24, 219-226.

21. Saunders C, Leal MC, Gomes MM et al. (2004) Gestational night blindness among women attending a public maternal hospital in Rio de Janeiro, Brazil. J Health Popul Nutr 22, 348-356.

22. Domingues RSMS, Dias MAB, Nakamura-Pereira M et al. (2014) Process of decision-making regarding the mode of birth in Brazil: from the initial preference of women to the final mode of birth. Cad Saude Publica 30, Suppl. 1, S101-S116.

23. Chagas CB, Ramalho A, Padilha PC et al. (2011) Reduction of vitamin A deficiency and anemia in pregnancy after implementing proposed prenatal nutritional assistance. Nutr Hosp 26, 843-850.

24. Neves PAR, Saunders C, Padilha PC et al. (2014) The role of prenatal nutrition assistance on the prevalence of night blindness in pregnant adults. Nutr Hosp 29, 1132-1140.

25. Institute of Medicine (2001) Dietary Reference Intakes for Vitamin A, Vitamin K, Arsenic, Boron, Chromium, Copper, Iodine, Iron, Manganese, Molybdenum, Nickel, Silicon, Vanadium, and Zinc. Washington, DC: National Academy Press.

26. World Health Organization (1996) Indicators for Assessing Vitamin A Deficiency and their Application in Monitoring and Evaluating Intervention Programmes. Geneva: WHO.

27. Saunders C, Ramalho RA, Lima APPT et al. (2005) Association between gestational night blindness and serum retinol in mother/newborn pairs in the city of Rio de Janeiro, Brazil. Nutrition 21, 456-461.

28. Miglioli TC, Fonseca VM, Gomes SC Jr et al. (2013) Deficiência de vitamina A em mães e filhos no estado de Pernambuco. Cienc Saude Colet 18, 1427-1440.

29. West KP Jr (2002) Extent of vitamin A deficiency among preschool children and women of reproductive age. J Nutr 132, 9 Suppl., 2857S-2866S.

30. Katz J, Khatry SK, West KP et al. (1995) Night blindness is prevalent during pregnancy and lactation in rural Nepal. J Nutr 125, 2122-2127.

31. Institute of Medicine (2009) Weight Gain During Pregnancy: Reexamining the Guidelines. Washington, DC: National Academies Press.
32. Brasil, Ministério da Saúde (2006) Pré-natal e Puerpério. Atenção Qualificada e Humanizada: Manual Técnico. Brasília: MS.

33. Lima S, Carvalho ML \& Vasconcelos AGG (2008) Proposta de modelo hierarquizado aplicado à investigação de fatores de risco de óbito infantil neonatal. Cad Saude Publica 24, 1910-1916.

34. Santos EM, Velarde LGC \& Ferreira VA (2010) Associação entre deficiência de vitamina A e variáveis socioeconômicas, nutricionais e obstétricas de gestantes. Cienc Saude Colet 15, 1021-1030.

35. Brasil, Ministério da Saúde, Secretaria de Atenção a Saúde, Departamento de Atenção Básica (2004) Vitamina A Mais: Programa Nacional de Suplementação de Vitamina A: Condutas Gerais. Brasília: MS.

36. World Health Organization (2011) Guideline: Vitamin A Supplementation in Pregnant Women. Geneva: WHO.

37. Rouse DJ (2003) Potential cost-effectiveness of nutrition interventions to prevent adverse pregnancy outcomes in the developing world. J Nutr 133, 5 Suppl. 2, 1640S-1644S.

38. Wrieden WL \& Symon A (2003) The development and pilot evaluation of a nutrition education intervention programme for pregnant teenage women (food for life). J Hum Nutr Diet 16, 67-71.

39. West KP Jr, Christian P, Katz J et al. (2010) Effect of vitamin A supplementation on maternal survival. Lancet 376, 873-874.

40. Semba RD, de Pee S, Panagides D et al. (2004) Risk factors of xerophthalmia among mothers and their children and for mother-child pairs with xerophthalmia in Cambodia. Arch Ophthalmol 122, 517-523.

41. Christian P, Katz J, Wu Lee et al. (2008) Risk Factors for pregnancy-related mortality: a prospective study in rural Nepal. Public Health 122, 161-172.

42. Tielsch JM, Rahmathullah L, Katz J et al. (2008) Maternal night blindness during pregnancy is associated with low birthweight, morbidity, and poor growth in South India. J Nutr 138, 787-792.

43. Checkley W, West KP Jr, Wise RA et al. (2010) Maternal vitamin A supplementation and lung function in offspring. $N$ Engl J Med 362, 1784-1794.

44. Simsek M, Naziroglu M, Simsek H et al. (1998) Blood plasma levels of lipoperoxides, glutathione peroxidase, $\beta$ carotene, vitamin $\mathrm{A}$ and $\mathrm{E}$ in women with habitual abortion. Cell Biochem Funct 16, 227-231.

45. Neela J \& Raman L (1997) The relationship between maternal nutritional status and spontaneous abortion. Natl Med J India 10, 15-16.

46. Maconochie N, Doyle P, Prior S et al. (2007) Risk factors for first trimester miscarriage - results from a UK-populationbased case-control study. BJOG 114, 170-186.

47. Penniston KL \& Tanumihardjo SA (2006) The acute and chronic toxic effects of vitamin A. Am J Clin Nutr 83, 191-201.

48. McLaren DS \& Frigg M (1999) Manual de Ver y Vivir sobre los Transtornos por Deficiencia de Vitamina A (VADD). Washington, DC: OPAS.

49. Brasil, Ministério da Saúde, Secretaria de Atenção à Saúde, Departamento de Atenção Básica (2013) Programa Nacional de Suplementação de Ferro: Manual de Condutas Gerais. Brasília: MS.

50. Silva CL, Saunders C, Szarfarc SC et al. (2012) Anaemia in pregnant women before and after the mandatory fortification of wheat and corn flours with iron. Public Health Nutr 15, 1802-1809. 